\title{
Working across Cultural Spheres: The Knowledge Sharing Practices of Boundary spanners in a Global Insurance Firm
}

\author{
Helena Heizmann \\ University of Technology Sydney
}

\begin{abstract}
As organisations are becoming increasingly complex from a cultural perspective, it is important to understand how practitioners manage the differences that arise when working with peers who engage in different cultural (national cultural, professional, functional) spheres. The purpose of this paper is to contribute to practice-based research on knowledge sharing by using a discourse analytic lens which exposes the link between the knowledge (sharing) practices of boundary spanners at cultural interfaces and its immediate power effects for the subjects involved. Drawing on the results of a qualitative study, the paper examines how a community of inhouse consultants in a global insurance firm shifts from translating to transformational knowledge sharing practices depending on the power relations that link them to their audiences. The study's findings highlight: (1) the political nature of boundary spanners' knowledge sharing practices, (2) the power effects for the subjects involved and (3) the relational character of communities of practice. The study suggests that knowledge (sharing) practices are not neutral but have power implications that need to be considered in cross-cultural boundary work if participants want to achieve more meaningful forms of mutual engagement.
\end{abstract}

\section{Introduction}

As Olsson (2014) has noted, traditional modernist views of the role of information and knowledge in cosmopolitan civil society are increasingly being challenged, making way for more practice-based, situated forms of exploration that recognise their socially constructed nature. From a research perspective, this requires an intent to understand 'a lived cosmopolitanism, which sees individuals of different cultures routinely negotiating across difference in order to coexist within a shared social space' (Onyx et al. 2011, p. 50). These 
negotiations occur at the interfaces of multiple cultures such as national culture, organisational culture, professional culture and/or functional culture (Sackmann 1997; Sackmann \& Phillips 2004; Saunders et al. 2010), involving complex cross-community boundary spanning situations where different knowledge(s), values and beliefs come into contact. Cross-cultural research increasingly recognises that such boundary work does not occur in a power vacuum, but rather transports, reinforces and/or transforms power relations that need to be considered if we are to better understand the nature of collaboration in a globalised world (Primecz, Romani \& Sackmann 2011). However, the link between power and knowledge (sharing) practices in bridging such 'cultural spheres' (Schneider \& Barsoux 2004) is not yet well understood (Hislop 2013).

This paper draws from the insights of a qualitative private sector study on organisational boundary spanners to provide a more comprehensive understanding of power effects in relation to knowledge sharing. The paper seeks to address the following research question: How are the knowledge (sharing) practices of boundary spanners at cultural interfaces connected to relations of power? In addressing this question, the paper offers insight into the knowledge sharing relationships between (1) Australian head office and Pacific Island staff (a cultural interface rarely explored in the knowledge management and cross-cultural communication literature, as well as (2) between Human Resources practitioners and line managers in various Australian business units. The paper contributes to the practice-based literature on knowledge sharing by using a discourse analytic lens which exposes the link between knowledge (sharing) practices and its immediate power effects for the subjects involved. It is argued that, rather than taking the cultural unity of organisations for granted, attention should be paid to the ways in which the knowledge practices of boundary spanners bring about a particular fabric of interdependencies between communities, discursive positions, and practices. The paper's findings highlight how boundary work involves the translation and/or transformation of knowledge at cultural interfaces.

While the notion of boundary spanning has its roots in corporate sector research (Aldrich \& Herker 1997; Ancona \& Caldwell 1992) the topic has been recognised as equally central to collaboration within and across third sector organisations (Isbell 2012; Leung 2013), thus the paper will discuss implications beyond its immediate locus of study. Following this introduction, the second section outlines the practice-based conceptual framework on knowledge sharing across multiple cultures (Sackmann 1997) or 'spheres’ (Schneider \& 
Barsoux 2004). The third section outlines the methodology of the study and presents its empirical findings. The fourth and fifth sections provide a discussion and conclusion.

\section{Conceptual Framework}

In recent years, the practice-based turn in the wider social sciences (Schatzki, Knorr-Cetina \& von Savigny 2001), practice-based studies in organisation studies (Gherardi 2000; Nicolini, Gherardi \& Yanow 2003), and the 'information practices' discourse in information studies (Savolainen 2007) have promoted a shift in perspective towards analysing workplace knowledge sharing not in functionalist-structural terms but by paying attention to the fluid social relations among practitioners that emerge from an engagement within and across shared domains of practice.

Conventional approaches conceptualise knowledge sharing and learning as the transfer of knowledge from a sending to a receiving person. They are rooted in the classic information transmission model, which views communication primarily as a mechanical process, in which a message is first constructed and encoded by a sender, then transmitted through a channel, and finally received and decoded by a receiver (Shannon \& Weaver 1949). Ever since the interpretive turn of the 1980s, this mechanistic view of communication has been increasingly criticised for conceptualising knowledge/information as a thing, which is first 'possessed by a sender and then dumped into the heads of receivers as though they were empty buckets' (Foreman-Wernet 2003, p. 5).

Applying a practice-based perspective to knowledge sharing means recognising that the activities which make up a social practice are only the 'tip of the iceberg'. Those activities 'emerge and become visible because lying beneath them is a mass of practical knowledge and discursive (material-semiotic) practices that justify practices as morally and aesthetically acceptable (Gherardi 2009, p. 123). Thus, from a practice-based perspective, knowledge sharing is not simply a matter of asking what, when, where and how knowledge is exchanged, but also of understanding what (and whose) knowledge is deemed legitimate in particular (organisational, professional, national cultural) domains of practice. What is accepted as 'good' practice is the outcome of negotiations about the authority of particular knowledge claims (Foucault 1980). 
Community of practice (CoP) theory challenges the idea that knowledge may be successfully 'internalised' without any engagement in social practice as learning is seen as a by-product of participation in CoPs (Lave \& Wenger 1991, p. 35). Lave and Wenger’s pioneering work on this topic defines a CoP as a 'set of relations among persons, activity, and world, over time and in relation with other tangential and overlapping communities of practice' (1991, p. 98). Through collaborating in shared practices, people become mutually engaged in a joint enterprise and develop a shared repertoire of cultural resources - they come to see the world through a particular lens (Wenger 1998). CoP members can thus share knowledge without an explicit articulation of the tacit dimension of knowledge, which is embedded in the shared context of practice. Conversely, in the absence of shared practices, knowledge is hard to transfer. 'It [specialised knowledge] becomes “sticky” and therefore dramatically tests the absorptive capacity of the receiver’ (Holden 2001, p. 159).

In the context of the global workplace, the 'stickiness' of knowledge constitutes particular issues when knowledge is shared across functions, national and regional offices, or organisations (Gherardi \& Nicolini 2002; Heizmann 2011, 2012; Sole \& Edmondson 2002). Interactions across such ‘cultural spheres’ (Schneider \& Barsoux 2004) or boundaries tend to be characterised by different identities, epistemic assumptions and world-views (Brown \& Duguid 1998, 2001; Carlile 2002, 2004).

\section{Multiple cultures and cross-boundary knowledge sharing}

The multiple cultures perspective emanates from an understanding of culture as a characteristic of all forms of collectives, including for instance the cultures of specific professional, industrial, ethnic, or gender groups (Sackmann 1997). Organisations are seen as complex settings in which many cultural 'spheres' (Schneider \& Barsoux 2004) may co-exist at the same time. Cross-boundary contact, from this perspective, involves the negotiation of meaning between different, sometimes competing and contesting values and beliefs, existing within different knowledge traditions and formations (Foucault 1972). As such, the cultural interface is a space which involves both the potential for cross-cultural synergy and conflict. In Nakata's words, as much as the cultural interface is

overlaid by various theories, narratives, and arguments that work to produce ... consensual, and co-operative social practices, it is also a space that abounds with contradictions, ambiguities, conflict and contestation of meanings (Nakata 2007, p. 199) 
One approach that can help to overcome the difficulties of collaboration across cultural spheres is the active involvement of boundary spanners who develop the social relationships between people from different communities of practice (Hislop 2009, p. 195). Such individuals need to understand the specialist domains of both communities and be trusted by its members in order to be able to assume the role of a knowledge broker or translator (Brown \& Duguid 1998).

Paul Carlile's work (2002, 2004) has been seminal in providing a theoretical framework for boundary spanning knowledge (sharing) practices. His empirical studies focus on knowledge sharing across organisational functional boundaries in the context of new product development. Based on an ethnographic study of four different units (sales/marketing; design engineering; manufacturing engineering; and production), Carlile was able to show that knowledge is structured and interpreted differently in different organisational areas. Of particular interest to this paper is his distinction between semantic and pragmatic boundaries. At a semantic boundary, knowledge sharing can be challenging as actors interpret the same knowledge differently. They will thus need to develop a mutual understanding of these interpretive differences - a process which boundary spanners can promote through the ‘translation’ of meaning. However, knowledge sharing becomes even more complex when actors do not only encounter different interpretations but also different interests that are 'at stake' (Carlile 2004, p. 559). Carlile describes such boundaries as pragmatic boundaries which require one party to change and/or adapt their knowledge ('transformation'). As we shall see in the study, boundary spanners can transform domain-specific knowledge by reframing it in the interests of target audiences.

\section{The Study}

\section{Data and methods}

The findings presented in this paper are drawn from an inductive case study (Yin 2009) which sought to explore knowledge sharing issues and enablers in a global insurance corporation with a particular focus on cultural interfaces. The study involved 17 semistructured, in-depth interviews with a group of in-house consultants in the area of Human Resources Business Partnering (HRBP), Learning and Development (L\&D), and Communications (Comms). This community of practitioners was considered particularly interesting for the purposes of the study since a large part of their work involved interacting 
across functional, regional, or national boundaries. Functionally, the consultants operated as part of the organisation's Human Resources (HR) group. Their tasks ranged from delivering staff induction seminars on corporate culture, planning and implementing leadership development, talent management, and workforce planning, to consulting specific business units on HR and communication matters. According to strategic documents, the joint purpose of these practitioners constituted the transformation of the organisation into a 'high performance organisation'. Starting with an initial group of five consultants who collaborated closely with each other, further participants were selected drawing on the participants' strong informal practice-related contacts through a snowball sampling method (Minichiello 1990). This sampling approach was considered particularly useful in order to identify a community of practitioners that was interconnected through their joint engagement in shared domain of practice (Wenger 1998).

All of the interviews were digitally recorded and lasted, on average, 60-90min. Interview studies have been criticised for eliciting mainly opinions rather than giving insight into behaviours (Kvale 1996, p. 292). The interviews therefore were guided by an approach that focuses on the participants' experiences of everyday work incidences, starting with descriptions of actual behaviours and, thereafter, exploring more closely the participants' interpretations of the situation (Sundin 2001) and what they saw as important in enabling successful knowledge sharing relationships. In addition, the study involved observation of meetings and staff induction workshops and sourcing of organisational documents to inform the interviews. The data were analysed with a critical-interpretive approach to discourse analysis (Heracleous 2004; Phillips \& Hardy 2002) and guided by the question of what discourse(s) dominated the participants' speech in the context of different knowledge sharing relations. To illustrate how the consultants' knowledge (sharing) practices were connected to power relations, I focus on two knowledge sharing relationships: (1) with staff in the company’s Pacific Island operations and (2) with line managers in various Australian business units. One limitation of the study was that it did not include the voices of the respective co-workers (e.g. line managers and Pacific Island co-workers). Therefore, an assessment of the impact of the consultants' knowledge (sharing) strategies from their counterparts’ perspective, i.e. whether they generated counter-narratives and resistance or compliance, did not form part of the analysis. 


\section{Findings}

The participants offered many examples that highlighted the difficulties of sharing knowledge when common frames of reference existed only partially or not at all. However, what became particularly evident was the presence of two differing discourses in the participants' accounts:

- a discourse around the need for corporate standards that was prominent when consultants spoke about their interactions with staff in the Pacific Island operations and

- a discourse of cultural adjustment that featured heavily when consultants spoke about their interactions with line managers of various business units in the Australian operations.

The 'corporate standards' discourse

One example of the corporate standards discourse could be seen when a consultant explained the difficulties of implementing HRM (Human Resource Management) policies in a subsidiary in Papua New Guinea to ensure regular office hours. According to the participant, discussing this type of information with local staff was a particularly challenging part of their role:

Sometimes you've got to deal with talking to someone about being always late, or taking additional time off over lunch. ...Some of them just, you know they don't realise that they've got to be in an office by a certain time. ....it's challenging to see that because here we are in Australia where we need to get to work on time, we've got an hour for lunch.

What is evident in this particular statement is a positioning of 'us' and 'them' where the behaviour of local staff ('them') is constructed as deviant from the standards set by the Australian head office operations. Another consultant related how working with staff in the Pacific Islands frequently required raising issues around dress code.

People turn up with sort of shorts and thongs because that's the culture over there, but it's not the company culture. So we have to sometimes reinforce what the company culture is and make sure that that sort of overrides the local culture, because the local culture is that you would turn up to work in shorts and thongs and a t-shirt.

Discursive claims such as 'we have to...reinforce' and 'they don't realise' were statements 
that attributed less power and authority to the cultural 'other'. In both examples, the construct of a homogenous company culture (shaped by head office standards) was drawn upon in legitimating the 'overriding' of local cultural practices.

When asked how they dealt with the tensions arising from efforts to establish corporate standards, participants highlighted the need to communicate messages in ways that they felt were sensitive to language barriers ('I did a lot of "so, what I'm hearing you say is”, “can I just check my understanding”?') and cultural differences ('We ended up sending out a bulk email with information about the dress code, because even though we knew who they were, you shouldn't single people out over there.') These examples showed an awareness of the complexities of interacting across cultural spheres and an adjustment in communication style. However, at the same time, this did not alter the prevailing influence of the corporate standards discourse in the consultants' speech with its hegemonic power effects on local staff.

\section{The 'cultural adjustment' discourse}

An important part of the participants' role was working with line managers across a number of business units of the Australian operations (e.g. IT, Finance, various insurance divisions) and supporting the implementation of a range of HRM practices (e.g. talent management, performance development, and engagement surveys). This involved working at the cultural interface of a number of professional and/or functional cultural spheres which were not always easily reconciled.

\footnotetext{
We might as well be speaking Dutch to these guys [IT]. You know, they don’t understand necessarily that language and the need for that change... And if you reverse that it would be the same. ... If someone from IT talks to me about what they do it’s "bla bla bla”, that's all I hear is "bla bla bla”.
}

The discourse that dominated the participants' speech when discussing their interactions with line managers could be characterised as a discourse of cultural adjustment. Contrary to the corporate standards discourse, the main emphasis was here on positioning themselves as 'partners' of management and 'influencing' line managers to accept HRM practices.

We set ourselves up as partners to work with the business and the key part of our role is to drive cultural change, help the business to manage their people better and get most out of their people.

And I guess as we aspire to become a High Performing organisation, do it through building relationships and influencing, rather than being enforcing. 
For instance, one participant explained how sharing knowledge was becoming increasingly challenging when interacting with line managers in other business units who were unfamiliar with, and perhaps less receptive to the HR 'philosophy'.

Within that world [of HR] we're pretty well connected now, and we have a fairly good understanding of what each different area is doing and what the key projects are ... we know the philosophy behind it. ... As you get further away from that circle of HR, there's less understanding of that. And so you have to do a lot more of that filling in of the why [emphasis added] and the process stuff about how we're doing it.

The participant's account highlights the need to explain, and more importantly, 'justify' HR initiatives when working with line managers - rendering the translation of knowledge into a matter of framing knowledge in the interests of the clients' perspectives. 'You'd wanna put it in their language if you can. So if you're trying to sell an idea you sell it through the business impact for example.' In a similar vein, a communications consultant related how he would always give written communications about a change project with the IT department to an IT practitioner for proof-reading. This was because he had realised that the IT group had their own way of verifying the 'veracity of information' which involved a thorough scrutinising of texts for everything which sounded like 'fluffy' HR talk. Asking for feedback was thus not simply a way of seeking input but also a mechanism of social legitimation. As credibility did not exist at the outset, it had to be established in a two-way process with people from within the IT community: 'I've learned that you must have a foot in either camp, if you're going to share knowledge.' What is evident in the previous examples is the consultants' intensified need for adapting knowledge (sharing) practices in a context where the authority of knowledge may be challenged. In contrast with their accounts of working with Pacific Island staff (characterised by efforts to assert dominance), the consultants' discourse manifested a struggle for equal partnership in their relations with line managers.

\section{Discussion}

The purpose of this paper was to examine the link between the knowledge (sharing) practices of boundary spanners at cultural interfaces and power relations. The discourse analytic focus on boundary spanners’ interpretations of their knowledge sharing relations revealed three important issues. 
Firstly, knowledge sharing at cultural interfaces is never a 'power-free' process as its participants operate in a broader socio-cultural and political context that shapes their discursive practices. As became evident in the findings, the consultants' prevailing discourse shifted depending on the cultural interface at which their boundary work was enacted: from a 'corporate standards' discourse that gave authority to cultural norms constructed by head office and positioned Pacific Island co-workers as the 'other' (Hall 2003); to a 'cultural adjustment' discourse that constructed a collective identity of partnership between consultants and line managers with the purpose of influencing line managers to adopt HRM practices. Intertwined with their discursive practices, the consultants' knowledge sharing practices shifted as well: from 'translating' practices (Carlile 2004) such as paraphrasing information, checking understanding among local staff and sending out explanatory emails about cultural norms; to ‘transformational' (Carlile 2004) practices such as adapting to their counterparts' (i.e. line managers') language and belief system, seeking to understand their needs in dialogue and using the received feedback to legitimate HRM knowledge. What becomes apparent is the following: how knowledge is shared and received in a cross-cultural boundary situation depends on processes of intersubjective validation among the parties who may switch flexibly between the discursive repertoires of different cultural spheres to legitimate their actions.

Secondly, the discursive practices at cultural interfaces are linked to immediate power effects for the subjects involved. As could be seen in the study's findings, the discursive shift from 'enforcing' to 'influencing' at the two cultural interfaces signalled (and reinforced) a shift in power relations and discursive positions among the consultants and their counterparts. In the case of working with staff in the Pacific Islands, the consultants attributed deviant behavior to ethnicity, engaging in a process of 'othering' (Hall 1997). In doing so, the consultants embodied (and relied on) the authority of a head office discourse which rendered the truth claims of local staff less powerful. Intra-organisational, geo-centric differences translated into power dynamics or, as Yanow (2004, p. S22) puts it: 'From the perspective of organizational 'centres', the further from the centre, the less power and status one is perceived to have and the less legitimacy is accorded to one's knowledge.' In the case of collaborating with line managers in various departments and occupational specialisations, the consultants' vantage point was a different one. Their focus was on influencing line managers to adopt HRM (rather than enforcing these practices), yet they also had to contend with line managers' resistance and instances in which the credibility of HRM knowledge came to be contested. 
This dynamic is perhaps best understood in the broader context of the precarious standing of HR professionals in relation to line managers highlighted in the HRM literature (Legge 1995; Wright 2008).

Finally, the study's findings highlight how the shift from practices of translation to practices of transformation (Carlile 2004) and its associated power dynamics have implications for the very nature of communities of practice. While the community of in-house consultants and their knowledge (sharing) practices could be seen as hegemonic in relation to Pacific Island staff, their relation with line managers was characterised by a much stronger dependency, given their need for managerial 'buy-in' in HRM. It is here that we can see the importance of a critique of functional-managerialist conceptions of communities of practice that reify the community, rather than recognising its relational character (Østerlund \& Carlile 2005). As Gherardi has noted, community and its boundaries should not be presupposed, but understood and studied as an effect that is 'realised through the discursive practices of its members' (Gherardi 2006, p. 110). The role of boundary spanners in this context has been overlooked and thus, drawing from the study's insights, it is suggested that future research pay more attention to the ways in which the knowledge practices of boundary spanners bring about a particular fabric of interdependencies between communities, discursive positions and practices.

\section{Broader implications}

The consultants' relations with Pacific Island staff did not appear to 'scale up' to the kind of meaningful connections envisaged from a perspective of everyday cosmopolitanism (Onyx et al. 2011) and it is hard to imagine how this would be realised within the constraints of hegemonic discourse. Boundary spanners need to build trust with their counterparts (Brown \& Duguid 1998) and this requires an interest in learning about cultural differences and a willingness to negotiate them in regular and sustained dialogic interactions (Isaacs 1999). In the case of the consultants' boundary work with line managers the consultants displayed a willingness to engage and transform knowledge, yet these efforts were not always reciprocated by their clients. As a result, the consultants' boundary work became predominantly about the legitimation of the HRM project (Mueller \& Carter 2005), rather than about realising more genuine forms of mutual engagement. 
While these power dynamics were prominent in the case organisation, they are not confined to the private sector. In spite of the participatory philosophy that commonly underpins crosscultural partnerships in the third sector, in practice, these are often undermined by perceptions of power and status differences that hinder two-way knowledge sharing and learning (Girgis 2007; Mansell 2010; Powell 2006). For instance, capacity development projects in developing countries require Western actors and their local counterparts to bridge existing power differentials (Heizmann, Fee, and Gray 2014). By using practice-based and discursive perspectives, future research in this area could go much further in exposing such power effects. Unpacking the discursive and socio-material practices in which people engage when working at cultural interfaces can be the starting point for social action, by (1) rendering visible the power relations and effects in which actors are involved, and (2) bolstering voices that have received limited legitimacy up to this point. On a more pragmatic level, such research could help uncover the boundary spanning strategies that actors draw upon to counter perceived power differentials and build more mutually engaged forms of collaboration.

\section{Conclusion}

The findings presented in this paper were gained through a qualitative methodology, which seeks to enrich and widen the body of in-depth contextual knowledge on a particular topic, rather than claiming statistical generalisability in and of itself (Kvale 1996, p. 289). As such, the links highlighted in this paper between the knowledge (sharing) practices of boundary spanners at cultural interfaces and power relations may offer impulses for the analysis of boundary work in a range of culturally complex spaces (e.g. aid \& development work, social movements, inter-organisational collaborations). What has become evident in the provided examples is that, when people cross cultural spheres, their collaboration efforts are situated within a discursively and politically shaped environment in which they cannot help but participate; indeed, it is the participants' narratives and discursive positioning that bring about particular forms of collaboration or non-collaboration, inclusion and exclusion (Hardy, Lawrence \& Grant 2005; Hardy \& Phillips 1999). Therefore, to reach more meaningful forms of cross-cultural interaction, participants need to engage openly with the discourses of their counterparts as well as be sensitive to the power effects of their own discursive practices. 


\section{References}

Aldrich, H. \& Herker, D. 1997, 'Boundary Spanning Roles and Organization Structure', Academy of Management Review, vol. 2, no. 2, pp. 217-30. doi: http://dx.doi.org/10.2307/257905

Ancona, D.G. \& Caldwell, D.F. 1992, 'Bridging the Boundary: External Activity and Performance in Oranizational Teams', Administrative Science Quarterly, vol. 37, no. 4, pp. 634-65. doi: http://dx.doi.org/10.2307/2393475

Brown, J.S. \& Duguid, P. 1998, 'Organizing Knowledge', California Management Review, vol. 40, no. 3, pp. 90-111. doi: http://dx.doi.org/10.2307/41165945

Brown, J.S. \& Duguid, P. 2001, 'Knowledge and Organization: A Social-Practice Perspective', Organization Science, vol. 12, no. 2, pp. 198-213. doi: http://dx.doi.org/10.1287/orsc.12.2.198.10116

Carlile, P.R. 2002, 'A Pragmatic View of Knowledge and Boundaries: Boundary Objects in New Product Development', Organization Science, vol. 13, no. 4, pp. 442-55. doi: http://dx.doi.org/10.1287/orsc.13.4.442.2953

Carlile, P.R. 2004, 'Transferring, Translating, and Transforming: An Integrative Framework for Managing Knowledge Across Boundaries', Organization Science, vol. 15, no. 5, pp. 555-68. doi: http://dx.doi.org/10.1287/orsc.1040.0094

Foreman-Wernet, L. 2003, 'Rethinking Communication: Introducing the Sense-Making Methodology', in B. Dervin \& L. Foreman-Wernet (eds), Sense-Making Methodology Reader. Selected Writings of Brenda Dervin, Hampton Press, Cresskill, pp. 3-16.

Foucault, M. 1972, The Archeology of Knowledge, Tavistock, London.

Foucault, M. 1980, Power/Knowledge: Selected Interviews \& Other Writings 1972-1977, Pantheon Books, New York.

Gherardi, S. 2000, 'Practice-Based Theorizing on Learning and Knowing in Organizations', Organization, vol. 7, no. 2, pp. 211-23. doi: http://dx.doi.org/10.1177/135050840072001

Gherardi, S., \& Nicolini, D. 2002, 'Learning in a Constellation of Interconnected Practices: Canon or Dissonance?', Journal of Management Studies, vol. 39, no. 4, pp. 419-36. doi: http://dx.doi.org/10.1111/1467-6486.t01-1-00298

Gherardi, S. 2006, Organizational Knowledge: The Texture of Workplace Learning, Blackwell Publishing, Malden. 
Gherardi, S. 2009, 'The Critical Power of the “Practice Lens”', Management Learning, vol. 40, no. 2, pp. 115-28. doi: http://dx.doi.org/10.1177/1350507608101225

Girgis, M. 2007, 'The Capacity-Building Paradox: Using Friendship to Build Capacity in the South', Development in Practice, vo. 17, no. 3, pp. 353-66. doi: http://dx.doi.org/10.1080/09614520701336782

Hall, S. 1997, 'The Work of Representation', in S. Hall (ed.), Representation. Cultural Representations and Signifying Practices, Sage, London, pp. 13-74.

Hall, S. 2003, 'The Spectacle of the 'Other", in S. Hall (ed.), Representation. Cultural Representations and Signifying Practices, Sage, London, pp. 223-90.

Hardy, C., Lawrence, T.B. \& Grant, D. 2005, 'Discourse and Collaboration: The Role of Conversations and Collective Identity', Academy of Management Review, vol. 30, no. 1, pp. 58-77. doi: http://dx.doi.org/10.5465/AMR.2005.15281426

Hardy, C. \& Phillips, N. 1999, 'No Joking Matter: Discursive Struggle in the Canadian Refugee System', Organization Studies, vol. 20, no. 1, pp. 1-24. doi: http://dx.doi.org/10.1177/0170840699201001

Heizmann, H. 2011, 'Knowledge Sharing in a Dispersed Network of HR Practice: Zooming in on Power/knowledge Struggles', Management Learning, vol. 42, no. 4, pp. 379-93. doi: http://dx.doi.org/10.1177/1350507610394409

Heizmann, H. 2012, 'Workplace Information Practices Among Human Resources Professionals: Discursive Boundaries in Action', Information Research, vol. 17, no. 3, Paper No. 532, http://InformationR.net/ir/517-533/paper532.html.

Heizmann, H., Fee, A., \& Gray, S. 2014, 'Effective Cross-cultural Capacity Development: The Importance of Boundary Contact Conditions.' Paper presented at the 28th Australian and New Zealand Academy of Management Conference ANZAM 2014, University of Technology, Sydney, Australia.

Heracleous, L. 2004, 'Interpretivist Approaches to Organizational Discourse', in D. Grant, C. Hardy, C. Oswick \& L. Putnam (eds), The Sage Handbook of Organizational Discourse, Sage, London, pp. 176-92. doi: http://dx.doi.org/10.4135/9781848608122.n8

Hislop, D. 2009, Knowledge Management in Organizations, 2nd edn, Oxford University Press, New York.

Hislop, D. 2013, Knowledge Management in Organizations: A Critical Introduction, 3rd edn, Oxford University Press, Oxford. 
Holden, N. 2001, 'Knowledge Management: Raising the Spectre of the Cross-Cultural Dimension', Knowledge and Process Management, vol. 8, no. 3, pp. 155-63. doi: http://dx.doi.org/10.1002/kpm.117

Isaacs, W.N. 1999, Dialogue and the Art of Thinking Together: A Pioneering Approach to Communicating in Business and in Life, Currency, New York.

Isbell, M.G. 2012, 'The Role of Boundary Spanners as the Interorganizational Link in Nonprofit Collaborating', Management Communication Quarterly, vol. 26, no. 1, pp. 159-65. doi: http://dx.doi.org/10.1177/0893318911423641

Kvale, S. 1996, Interviews. An Introduction to Qualitative Research Interviewing, Sage Publications, Thousand Oaks.

Lave, J. \& Wenger, E. 1991, Situated Learning: Legitimate Peripheral Participation, Cambridge University Press, Cambridge. doi: http://dx.doi.org/10.1017/CBO9780511815355

Legge, K. 1995, 'HRM: Rhetoric, Reality and Hidden Agendas', in J. Storey (ed.), Human Resource Management: A Critical Text, Routledge, New York, pp. 33-59.

Leung, Z.C.S. 2013, 'Boundary Spanning in Interorganizational Collaboration', Administration in Social Work, vol. 37, no. 5, pp. 447-57. doi: http://dx.doi.org/10.1080/03643107.2013.827999

Mansell, R. 2010, 'Power and Interests in Developing Knowledge Societies: Exogenous and Endogenous Discourses in Contention', IKM Working Paper, no. 11.

Minichiello, V. 1990, In-depth Interviewing. Researching People, Longman Cheshire, South Melbourne.

Mueller, F. \& Carter, C. 2005, 'The "HRM project” and Managerialism - Or Why Some Discourses Are More Equal Than Others', Journal of Organizational Change, vol. 18, no. 4, pp. 369-82. doi: http://dx.doi.org/10.1108/09534810510607065

Nakata, M. 2007, Disciplining the Savages. Savaging the Disciplines, Aboriginal Studies Press, Canberra.

Nicolini, D., Gherardi, S. \& Yanow, D. (eds) 2003, Knowing in Organizations: A Practicebased Approach, Sharp, New York.

Olsson, M. 2014, 'Information Practices in Contemporary Cosmopolitan Civil Society', Cosmopolitan Civil Societies: An Interdisciplinary Journal, vol. 6, no. 2, pp. 69-93. doi: http://dx.doi.org/10.5130/ccs.v6i2.3948

Onyx, J., Ho, C., Edwards, M., Burridge, N. \& Yerbury, H. 2011, 'Scaling Up Connections: Everyday Cosmopolitanism, Complexity Theory \& Social Capital', Cosmopolitan 
Civil Societies Journal, vol. 3, no. 3, p. 50. doi:

http://dx.doi.org/10.5130/ccs.v3i3.2180

Østerlund, C. \& Carlile, P. 2005, 'Relations in Practice: Sorting Through Practice Theories on Knowledge Sharing in Complex Organizations', The Information Society, vol. 21, no. 2, pp. 91-107. doi: http://dx.doi.org/10.1080/01972240590925294

Phillips, N. \& Hardy, C. 2002, Discourse Analysis. Investigating Processes of Social Construction, Sage, Thousand Oaks.

Powell, M. 2006, 'Which Knowledge? Whose Reality? An Overview of Knowledge Used in the Development Sector', Development in Practice, vol. 16, no. 6, pp. 518-32. doi: http://dx.doi.org/10.1080/09614520600957951

Primecz, H., Romani, L. \& Sackmann, S. (eds) 2011, Cross-cultural Management in Practice: Culture and Negotiated Meanings, Edward Elgar Publishing Limited, Cheltenham. doi: http://dx.doi.org/10.4337/9780857938725

Sackmann, S. (ed.) 1997, Cultural Complexity in Organizations; Inherent Contrasts and Contradictions, Sage, Thousand Oaks.

Sackmann, S. \& Phillips, M.E. 2004, 'Contextual Influences on Culture Research: Shifting Assumptions for New Workplace Realities', International Journal for CrossCultural Research, vol. 4, no. 3, pp. 371-92. doi: http://dx.doi.org/10.1177/1470595804047820

Saunders, M.N.K., Dietz, G., Gillespie, N. \& Lewicki, R.J. (eds) 2010, Organizational Trust. A Cultural Perspective, Cambridge University Press, New York. doi: http://dx.doi.org/10.1017/CBO9780511763106

Savolainen, R. 2007, 'Information Behavior and Information Practice: Reviewing the "Umbrella Concepts" of Information-Seeking Studies', The Library Quarterly, vol. 77, no. 2, pp. 109-32. doi: http://dx.doi.org/10.1086/517840

Schatzki, T., Knorr-Cetina, K. \& von Savigny, E. (eds) 2001, The Practice Turn in Contemporary Theory, Routledge, London.

Schneider, S.C. \& Barsoux, J.L. 2004, Managing Across Cultures, Prentice Hall, London.

Sundin, O. 2001, 'Information Strategies and Professional Identity: A Study of Nurses' Experiences of Information at the Workplace', Information Research, vol. 6, no. 2, pp. retrieved 20 May, 2010, from http://informationr.net/ir/6-2/ws6.html .

Wenger, E. 1998, Communities of Practice: Learning, Meaning, and Identity, Cambridge University Press, Cambridge. doi: http://dx.doi.org/10.1017/CBO9780511803932 
Wright, C. 2008, 'Reinventing Human Resource Management: Business Partners, Internal Consultants and the Limits to Professionalization', Human Relations, vol. 61, no. 8, pp. 1063-86. doi: http://dx.doi.org/10.1177/0018726708094860

Yanow, D. 2004, 'Translating Local Knowledge at Organizational Peripheries', British Journal of Management, vol. 15, pp. S9-S25. doi: http://dx.doi.org/10.1111/j.14678551.2004.t01-1-00403.x

Yin, R. K. 2009, Case Study Research. Design and Methods (4th ed.), Sage, Thousand Oaks. 